\title{
Bazı Yağlık Ayçiçeği (Helianthus annuus L,) Genotiplerinin Erzurum Ekolojik Koşullarında Adaptasyon Kabiliyetlerinin Belirlenmesi
}

\begin{tabular}{l|r}
\hline $\begin{array}{l}\text { Araştırma / Research } \\
\text { Gelis Tarihi / Received } \\
\text { 31.10.2017 }\end{array}$ & \\
$\begin{array}{l}\text { Kabul Tarih / Accepted } \\
\text { 18.01.2018 }\end{array}$ & Firat SEFAOĞLU*, Canan KAYA \\
DOI & Doğu Anadolu Tarımsal Araştırma Enstitüsü Müdürlüğü, Erzurum/Turkey \\
10.28955/alinterizbd.348071 & *e-posta: firatsefaoglu@ @otmail.com \\
$\begin{array}{l}\text { ISSN 2564-7814 } \\
\text { e-ISSN 2587-2249 }\end{array}$ & \\
\hline
\end{tabular}

Öz: Bu çalışma, Erzurum ekolojik koşullarına uygun yağlık ayçiçeği genotiplerinin belirlenmesi amacıyla, 2015 yetiştirme sezonunda tesadüf blokları deneme desenine göre 4 tekerrürlü olarak Erzurum/Pasinler ekolojik koşullarında yürütülmüş̧ür. Çalışmanın materyalini TTAE ayçiçeği ıslah programınca geliştirilen yağlık hibrit hatlar (ERZ 10-3, ERZ 10-8, ERZ 10-1, ERZ 10-24, ERZ 10-11, ERZ 12-12 ve ERZ 11-20) ve ticari çeşitler (LG 5580, BOSFORA VE 08 TR 003) oluşturmuştur. Çalışma sonucuna göre, tane verimi, yağ oranı, yağ verimi, bin tane ağırlığı, bitki boyu ve tabla çapı bakımından çeşitler ve hatlar arasında önemli $(p<0,01)$ farkların bulunduğu saptanmıştır. En yüksek tohum ve ham yă̆ verimi BOSFORA çeşidinden $\left(279,8 \mathrm{~kg} \mathrm{da}^{1}\right.$ ve $\left.111,9 \mathrm{~kg} \mathrm{da}^{-1}\right)$, en yüksek ham yağ oranı 08 TR 003 (\% $41,2)$ ve ERZ 10-24 $(\% 40,8)$ hattından elde edilmiştir. En düşük tohum verimi $\left(146,9 \mathrm{~kg} / \mathrm{da}^{1}\right)$, ham yağ oranı $(\% 30,5)$ ve ham yağ verimi $\left(44,8 \mathrm{~kg} \mathrm{da}^{-1}\right)$ ERZ 10-3 hattından alınmıştır. Araştırma sonuçları verim performansları bakımından ERZ 10-11 ve ERZ 10-24 hatlarının verim ve kalite açısından umut verici olduğunu ve bu hatlar ile çalışmalara devam edilmesinin uygun olacağını ortaya koymaktadır.

Anahtar Kelimeler: Yağlı ayçiçeği, Helianthus annuus L., tane verimi, yağ oranı

\section{Determınation of Adaptation Capabilities of Some Oil Sunflower (Helianthus annuus L,) Genotypes in Erzurum Ecological Conditions}

\begin{abstract}
This study was carried out under the ecological conditions of Erzurum/Pasinler with four replications according to randomized blocks trial design in the 2015 raising season, in order to determine suitability of the oil sunflower genotypes for Erzurum ecological conditions. The material of the study was oil-hybrid lines (ERZ 10-3, ERZ 10-8, ERZ 10-1, ERZ 10-24, ERZ 10-11, ERZ 12-12 ve ERZ 11-20) and commercial varieties (LG 5580, BOSFORA ve 08 TR 003) that developed by the TTAE sunflower breeding program, According to the result of the study, significant differences $(p<0,01)$ exist among varieties and lines in terms of grain yield, oil ratio, oil yield, grain weight, plant height and table diameter. The highest seed and crude oil yield was obtained from BOSFORA (279,8 $\mathrm{kg}$ da1 and $\left.111,9 \mathrm{~kg} \mathrm{da}^{-1}\right)$ cultivars. The highest ratio oil was obtained from 08 TR $003(41,2 \%)$ and ERZ 10-24 (40,8\%) line. The lowest seed yield $\left(146,9 \mathrm{~kg} \mathrm{da}^{-1}\right)$, crude oil ratio $(30,5 \%)$ and crude oil yield $\left(44,8 \mathrm{~kg} \mathrm{da}^{-1}\right)$ were obtained from the ERZ 10-3 line. The results of the study on occount of efficiency performance show that ERZ 10-11 and ERZ 10-24 lines candidates are promising in terms of yield and quality and reveals that continue to work with this lines is appropriate .
\end{abstract}

Key Words: Sunflower oil, Helianthus annuusl., seed yield, oil ratio

Lütfen aşağıdaki şekilde atıf yapınız / Please cite this paper as follows:

Sefaoğlu, F., \& Kaya, C., 2018. Bazı Yağlık Ayçiçeği (Helianthus annuus L,) Genotiplerinin Erzurum Ekolojik Koşullarında Adaptasyon Kabiliyetlerinin Belirlenmesi. Alınteri Journal of Agriculture Sciences, 33(1): 37-41

\section{GİRis}

Temel besin kaynaklarından olan yağlar, insan beslenmesinde ve yaşamsal faaliyetlerin yerine getirebilmesinde gerekli olan temel besin maddelerinden birisidir. AB ülkelerinde kişi başına yıllık yağ tüketimi $24 \mathrm{~kg}_{\mathrm{y} 11^{-1}} \mathrm{civar}^{\mathrm{v}} \mathrm{nda}$ iken ülkemizde kişi başına yıllık toplam yağ tüketimi konusunda çok farklı veriler bulunmakla birlikte, bu değerin

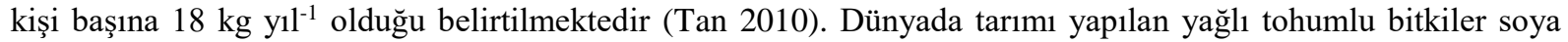
fasulyesi, yer fıstığı, ayçiçeği, kanola (kolza), mısır, zeytin, susam, palmiye tohumu, yağ keteni, aspir, hindistan cevizi ve hintyağı'dır. Üretim miktarlarına bakıldığında ise en yoğun üretimi yapılan soya fasulyesi, kanola, pamuk tohumu, yer fistığı, ayçiçeği ve palm yağıdır. Ülkemizde yetiştiriciliği yapılan yağ bitkileri ayçiçeği, çiğit, soya, yer fistığı, haşhaş, susam, kolza ve aspir'dir. Gün uzunluğuna duyarsız olması, kurağa ve düşük sıcaklıklara dayanıklı oluşu, kumludan killiye kadar değişen birçok toprak tipinde iyi yetişmesi ayçiçeğinin çok farklı çevrelere adapte olmasını sağlar. Bu özellikleri bitkiyi diğer yă̆ bitkilerinden üstün kılmaktadır (Carter 1978). Ayrıca yüksek yağ oranı (\%45-50) ve yağ kalitesiyle ülkemizde yağ bitkileri üretiminde başta Trakya, Ege, İç Anadolu ve Karadeniz Bölgesi olmak üzere son y1llarda Çukurova ve Geçit bölgelerinde üretimi giderek artmaktadır. Ayçiçeği 2016 y1lında ülkemiz genelinde 6,167,800 da alanda ekilerek 1,500,000 ton yağlı üretim 
gerçekleşmiştir. Aynı yıl Doğu Anadolu bölgesinde 20,030 da alanda 4,158 ton yağlık ayçiçeği üretimi yapılmakta iken, Erzurum'da 575 da alanda toplam 180 ton yağlık ayçiçeği üretimi yapılmıştır. Ortalama verim, Türkiye, Doğu Anadolu Bölgesi ve Erzurum'da sırasıyla $208 \mathrm{~kg} \mathrm{da}^{-1}, 224 \mathrm{~kg} \mathrm{da}^{-1} \mathrm{ve} 313 \mathrm{~kg} \mathrm{da}^{-1}$ olarak gerçekleşmiştir (Tüik 2016). Ülkemizde özellikle her yıl hissedilir derecede artarak devam eden bitkisel yăg açı̆̆ımız, bugün bitkisel yağ sanayimizin, dolayısıyla ülke ekonomimizin önemli problemleri içerisinde yer almaktadır. Üretim artışının talepteki artış hızını yakalayamaması; Türkiye'yi hem yağ hem de yağlı tohum ithalatçısı haline getirmiştir. Nüfusun giderek artması yağ tüketimindeki artışı da beraberinde getirecek ve ithalattaki artış kaçınılmaz olacaktır. Söz konusu açığın kapatılabilmesi için ayçiçeği ve diğer yağlı tohumlu bitkilerin üretiminin artırılması gerekmektedir. Ayçiçeğinde üretim artışı, ekim alanlarının genişletilmesi ve yüksek verim potansiyeline sahip ayçiçeği çeşitlerinin üretimde yer alması ile mümkün olacaktır.

Yağlık ayçiçeği Doğu Anadolu Bölgesinin sulanabilir alanlarının önemli bir münavebe bitkisi olduğu düşünülmektedir. Küspesi değerli bir hayvan yemi olan yağlık ayçiçeği üretiminin artması ile ayrıca bölgede ki yem fabrikalarına hammadde sağlanmasında önemli bir unsur olacaktır. Bu durum bölgede önemli bir geçim kaynağı olan hayvancılığa destek verirken, mevcut fabrikaların kapasite arttırması ve yeni tesislerin açılması işsizliği önlemede katkı sağlayacaktır. Bitkisel üretimin artması ve buna paralel olarak tarımsal sanayinin bölgede gelişmesi istihdam sağlayarak göçü nispeten önleyebilecek unsurlardan birisi olacaktır.

Doğu Anadolu bölgesinde yağlık ayçiçeği yetiştiriciliğine yönelik yapılan birçok çalışma bölge için iyi bir münavebe bitkisi olabileceğini göstermektedir (Özer ve ark., 2003; Tozlu ve ark.,2008; Sefaoğlu ve ark., 2009; Yıldız ve ark., 2009; Albayrak, 2014; Karakuş ve ark., 2014).

TTAE Ayçiçeği ıslah programı kapsamında ıslah edilen hibrit ayçiçeği çeşit adaylarının Erzurum ekolojik koşullarında performanslarının belirlenerek, öne çıkan aday veya adayların belirlenmesi ve ilerleyen yıllarda üretime kazandırılması bu çalışmanın asıl amacını oluşturmaktadır.

\section{MATERYAL VE YÖNTEM}

Araştırmada, Doğu Anadolu Tarımsal Araştırma Enstitüsü Pasinler Deneme İstasyonunda 2015 yetiştirme sezonunda adaptasyon yeteneklerinin belirlenmesi amacıyla denemeye alınan 7 adet çeşit adayı (ERZ 10-3, ERZ 10-8, ERZ 10-1, ERZ 10-24, ERZ 10-11, ERZ 12-12 VE ERZ 11-20) ve 3 adet tescilli çeşit (LG 5580, BOSFORA VE 08 TR 003) materyal olarak kullanılmıştır.

Deneme alanı toprağının, tınlı, hafif alkali, kireç oranı \%0,65, organik madde oranı \%1,38, fosfor miktarı 11,99 $\mathrm{kg} \mathrm{da}^{-1}$ ve potasyum miktarının $372 \mathrm{~kg} \mathrm{da}^{-1}$ olduğu belirlenmiştir. Araştırmada materyal olarak kullanılan çeşitlerin yetiştirildiği 2015 yılı vejatasyon süresinde (Nisan-Eylül) düşen toplam yağış miktarı $(220,9 \mathrm{~mm}) \mathrm{uzun}$ yıllar (1975-2014) yağış ortalamasının $(243,9 \mathrm{~mm})$ altında gerçekleşmiştir. Uzun yıllar ile 2015 yılı vejatasyon döneminde (Nisan- Eylül) gerçekleşen ortalama sıcaklıklar ise sırasıyla 15,3 ve 16,6 olarak belirlenmiştir (Çizelge 1).

Çizelge 1. Erzurum/merkez Lokasyonu 2015 Yılına Ait Bazı İklim Verileri

\begin{tabular}{lccccccc}
\hline & Yıllar & \multicolumn{7}{c}{ Aylar } \\
\hline İklim Değerleri & & Nisan & Mayıs & Haziran & Temmuz & Ağustos & Eylül \\
\hline Toplam yağış, $\mathbf{~ m m ~}$ & 2015 & 31,6 & 88,6 & 21,6 & 27,8 & 3,6 & 47,7 \\
\hline & UY & 53,5 & 73,1 & 49,1 & 26,8 & 17,5 & 23,9 \\
\hline Nispi nem, $\%$ & 2015 & 64,5 & 68,7 & 54,9 & 46,9 & 39,6 & 48,3 \\
\hline & UY & 68 & 63,9 & 59,1 & 53,7 & 50,4 & 52,7 \\
\hline Ortalama sıcaklık, $^{\mathbf{0}} \mathbf{C}$ & 2015 & 7,5 & 11,3 & 15,3 & 20,6 & 21,4 & 15,7 \\
\hline & UY & 5,3 & 10,7 & 14,9 & 19,3 & 19,5 & 13,2 \\
\hline
\end{tabular}

Araştırma, Erzurum/Pasinler şartlarında, tesadüf blokları deneme desenine göre, 4 tekerrürlü olarak düzenlenmiştir. Parsel alanı 8,1x2,8=22,68 $\mathrm{m}^{2}$ 'dir, Her parsel 4 sıradan, her sıra ise 27 Ocaktan oluşmuştur. Ekim, 13 Mayıs 2015 tarihinde 70x30 cm sıra aralık mesafesinde elle yapılmıştır. Deneme alanına, dekara $10 \mathrm{~kg} \mathrm{~N}$ ve 8 $\mathrm{kg} \mathrm{P}_{2} \mathrm{O}_{5}$ hesab1 ile gübre uygulaması yapılmıştır. Azotlu gübre olarak amonyum sülfat, fosforlu gübre olarak triple süper fosfat kullanılmıştır. Azotun yarısı ekimle birlikte diğer yarısı ise çıkıştan sonra elle parsellere uygulanmıştır. Sulama, çiçeklenme döneminde olmak üzere 2 defa yapılmıştır. Tablaların arkasının kahverengiye dönüştüğü ve tohumların tamamının olgunlaştığı devrede hasat başlamıştır (30 Eylül 2015). Hasatta kenarlardan birer sıra ve baş kısmından birer bitki kenar tesiri olarak değerlendirilmiş ve merkezde kalan 2 sıradaki bitkiler el ile hasat edilmiştir (Tunçtürk ve ark., 2005). Daha sonra hasat edilen tablalar kurutulduktan sonra dövülerek ayçiçeği taneleri çıkarılmış, gerekli sayım ve tartımlar yapılmıştır. 
Araştırmadan elde edilen verilerin varyans analizleri JMP 7,0 (Copyright (C) 2007SAS Institute Inc,) paket programı kullanılarak yapılmış, önemli bulunan faktör ortalamaları LSD testi ile gruplandırılmıştır.

\section{ARASTTIRMA BULGULARI VE TARTIŞMA}

$\mathrm{Bu}$ araştırmanın sonuçlarına göre, incelenen özellikler bakımından ayçiçeği genotipleri arasında istatistiki olarak $(\mathrm{p}<0,05$ veya $\mathrm{p}<0,01)$ önemli farklılıkların olduğu ve incelenen tüm özelliklerin ortalama değerleri ile bu ortalamaların istatistikî olarak arz ettiği önem Çizelge 2'de verilmiştir. Denemeye alınan ayçiçeği çeşit ve hatlarında;

\section{Tabla Çapı}

Araştırmada ele alınan ayçiçeği çeşitleri ve hatlarına ait tabla çapları arasında istatistiki olarak $\mathrm{p}<0,01$ seviyesinde farklılıklar belirlenmiştir. Tabla çapı en yüksek ERZ 10-11'de (20,7 cm) tespit edilirken en düşük tabla çapı ERZ 11-20 hattında (16,0 cm) ölçülmüştür. Bu çalışma sonucunda belirlenen tabla çapı değerleri Kara (1986) ve Gül (2015)'ün belirlediği değerler ile benzer, Demirel (2014)' in değerlerinden yüksek çıkmıştır. Bölge şartlarında yapılan çalışmalarda da tabla çapının 15,9-22,3 cm arasında değiştiği bildirilmiştir (Özer ve ark., 2003; Sefaoğlu ve ark., 2009; Yıldız ve ark., 2009; Kara ve ark., 2013).

\section{Bitki Boyu}

Çalışmada en yüksek bitki boyu ERZ 10-8 hattında (166,5 cm) ölçülürken, en kısa değer 08 TR 003 (125,4 cm) çeşidinden elde edilmiştir. Çeşit ve hatların bitki boylarına ait varyans analizi sonucunda oluşan farklılıklar $\mathrm{P}<0,01$ ihtimal seviyesinde önemli bulunmuştur. Bitki boyu çeşitlere ekolojik şartlara, ve tarımsal uygulamalara göre farklılık göstermektedir. Tan (2014) uzun, orta, kısa ve bodur boylu bir ayçiçeği çeşidinin bitki boyu üzerine sulama, ekim zamanı, bitki sıklığı ve çevresel faktörlerin rol oynadığını bildirmiştir. Çeşitlerin farklı bitki boylarına sahip olması genetik özelliklerinden kaynaklanabilir. Kara (1986) ayçiçeği çeşitlerin bitki boylarının 128,5-176,1 cm; Karaaslan (2003), 124,5-158,9 cm Sefaoğlu ve ark., (2009), 130,9-161,0 cm arasında değiştiğini tespit etmişılerdir. Çalışma bulguları araştırmacıların bildirdiği sonuçlarla uyum içerisindedir. Çalışmalar arasında az çok görülen farlılıkların nedeni, kullanılan genotiplerin gen yapısına ve ekolojik faktörlere bağlanabilir.

Çizelge 2. Denemeye Alınan Ayçiçeği Çeşit ve Hatların İncelenen Özelliklerine Ait Ortalama Değerler,

\begin{tabular}{|c|c|c|c|c|c|c|}
\hline $\begin{array}{l}\text { Çeşit adayı/ } \\
\text { Çeşit ismi }\end{array}$ & $\begin{array}{c}\text { Tabla Çapı } \\
(\mathrm{cm})\end{array}$ & $\begin{array}{l}\text { Bitki Boyu } \\
\text { (cm) }\end{array}$ & $\begin{array}{c}\text { Bin Tane } \\
\text { Ağırlığı (g) }\end{array}$ & $\begin{array}{c}\text { Tane Verimi } \\
\left(\mathrm{kg} \mathrm{da}^{-1}\right)\end{array}$ & $\begin{array}{c}\text { Yağ Oranı } \\
(\%)\end{array}$ & $\begin{array}{c}\text { Yăg Verimi } \\
\left(\mathrm{kg} \mathrm{da}^{-1}\right)\end{array}$ \\
\hline LG 5580 & $17,5 \mathrm{bd}$ & $148,9 \mathrm{bd}$ & $47,2 \mathrm{de}$ & $231,7 \mathrm{bc}$ & $41,1 \mathrm{ab}$ & $95,1 \mathrm{ac}$ \\
\hline BOSFORA & $18,2 \mathrm{~b}$ & $147,2 \mathrm{~cd}$ & $59,7 \mathrm{~b}$ & $279,8 \mathrm{a}$ & $40,0 \mathrm{ab}$ & $111,9 \mathrm{a}$ \\
\hline 08 TR 003 & $18,4 \mathrm{~b}$ & $125,4 \mathrm{e}$ & $71,0 \mathrm{a}$ & $213,8 \mathrm{bc}$ & $41,2 \mathrm{a}$ & 88,0 bd \\
\hline ERZ 10-3 & $18,1 \mathrm{~b}$ & $156,7 \mathrm{ac}$ & $44,3 \mathrm{de}$ & $146,9 \mathrm{~d}$ & $30,5 \mathrm{f}$ & $44,8 \mathrm{~g}$ \\
\hline ERZ 10-8 & $16,9 \mathrm{bd}$ & $166,5 \mathrm{a}$ & $46,1 \mathrm{de}$ & $208,5 b c$ & $37,7 \mathrm{bd}$ & $78,6 \mathrm{ce}$ \\
\hline ERZ 10-1 & $16,2 \mathrm{~cd}$ & $160,9 \mathrm{ab}$ & $50,2 \mathrm{~cd}$ & $195,9 \mathrm{c}$ & 36,5 ce & $71,6 \mathrm{de}$ \\
\hline ERZ 10-24 & $17,9 \mathrm{bc}$ & $151,1 \mathrm{bd}$ & 47,6 ce & $244,0 \mathrm{ab}$ & $40,8 \mathrm{ab}$ & $99,6 \mathrm{ab}$ \\
\hline ERZ 10-11 & $20,7 \mathrm{a}$ & $143,8 \mathrm{~d}$ & $53,54 \mathrm{c}$ & $245,4 \mathrm{ab}$ & $38,9 \mathrm{ac}$ & $95,5 \mathrm{ac}$ \\
\hline ERZ 12-12 & $17,7 \mathrm{bd}$ & $141,8 \mathrm{~d}$ & $41,8 \mathrm{e}$ & $195,3 \mathrm{c}$ & $34,9 \mathrm{de}$ & 68,3 ef \\
\hline ERZ 11-20 & $16,0 \mathrm{~d}$ & $145,5 \mathrm{~cd}$ & $45,9 \mathrm{de}$ & $155,3 \mathrm{~d}$ & 33,8 ef & $52,4 \mathrm{fg}$ \\
\hline Hat, & $*$ & $*$ & $*$ & $*$ & $*$ & $*$ \\
\hline Ortalama & 17,7 & 148,8 & 50,8 & 211,7 & 37,5 & 80,6 \\
\hline $\mathrm{C}, \mathrm{V},(\%)$ & 7,0 & 5,0 & 8,0 & 12,0 & 6,0 & 14,0 \\
\hline LSD (\%) & 1,8 & 12,6 & 6,0 & 38,2 & 3,4 & 17,4 \\
\hline
\end{tabular}

*istatistiki olarak \%5'te önemli $(\mathrm{P}<0,05)$; **istatistiki olarak \%1'de önemli $(\mathrm{P}<0,01)$; Farklı harflerle gösterilen ortalamalar arasındaki fark önemlidir,

\section{Bin Tane Ă̆ırlığı}

En önemli verim unsurlarından biri olan 1000 tane ağırlığı çeşide ve yetiştirme şartlarına göre değişiklik göstermektedir. Araştırmada ayçiçeği genotiplerinin 1000 tane ağırlıkları arasındaki farklılıklar p<0,01 ihtimal sınırında önemli bulunmuştur. Genotiplere göre bin tane ağırlığ 41,8-71,0 g arasında değişiklik göstermiştir. Çalışmada en yüksek bin tane ağırlığı 08 TR 003 (71,0 g) çeşidinden en düşük bin tane ağırlığı ise ERZ 12-12 (41,8 g) hattında belirlenmiştir. Yapılan farklı araştırmalarda (Çil ve ark., 2011; Evci ve ark., 2011; Sefaoğlu ve ark., 2009; Yıldız ve ark., 2009; Kara ve ark., 2013 ve Albayrak, 2014) bin tane ağırlıkları 38-83 g arasında değiştiği belirtilmiştir. $\mathrm{Bu}$ çalışmadan elde edilen değerler araştırmacıların bildirdiği sonuçlarla benzerlik 
göstermektedir. Bin tane ağırlıklarındaki rakamsal farklılıkların, çeşitlerin genetik yapısından, uygulanan yetiştirme tekniklerinden, iklim ve ekim zamanından kaynaklanabileceği bildirilmiştir ( Oral ve Kara, 1989; Esechie ve ark., 1996).

\section{Tane Verimi}

Ayçiçeğinin verim özellikleri üzerine etkili olan en önemli faktörlerden birinin çeşit olduğu bilinmektedir (Andrei et al, 1992). Genotiplere göre ortalama tane verimi $146,9-279,8 \mathrm{~kg} \mathrm{da}^{-1}$ arasında değişmiştir. En yüksek tane verimi Bosfora çeşidi (279,8 $\left.\mathrm{kg} \mathrm{da}^{-1}\right)$ ve ERZ 10-11 hattından $\left(245,4 \mathrm{~kg} \mathrm{da}^{-1}\right)$ elde edilirken, en düşük tane verim değeri ERZ 10-3 hattından (146,9 $\mathrm{kg} \mathrm{da}^{-1}$ ) elde edilmiştir. Diğer bitkilerde olduğu gibi ayçiçeğinde de verim, çeşit ve çevre koşullarından önemli derecede etkilenmektedir. Çeşitlerin tane veriminin farklı olması çeşitlerin verim potansiyeline bağlıdır buda genotipik yapılarının farklılığından kaynaklanmaktadır. Bir başka ifadeyle çeşit farklılıklarının oluşmasında ekolojik faktörlerin ve yetiştirme koşullarının da dikkate alınması gerekmektedir (Sefaoğlu ve ark., 2009). Farklı genotiplerle benzer ve değişik ekolojilerde yapılan çalışmalarda değişik tane verim sonuçları alınmıştır. Bu çalışma sonucunda elde edilen tane verimleri Sefaoğlu ve ark.,(2009), Evci ve ark., (2011), Albayrak (2014), Gül (2015) sonuçlarından düşük çıkarken, Özer (1999) tarafından yapılan çalışmanın sonuçları ile benzerlik göstermektedir.

\section{Yağ Oranı Ve Yă̆ Verimi}

Denemede incelenen genotipler arasında yağ oranı bakımından $\mathrm{p}<0,05$ ihtimal seviyesinde istatistiksel farklılıklar belirlenmiştir. En yüksek yağ oranı O8 TR 003 çeşidinden (\% 41,2) alınırken, en düşük yă̆ oranı ERZ 10-3 hattından $(\% 30,5)$ alınmıştır. Yağ oranı üzerine birçok faktörün etki ettiğini ve genotipler arasında görülen farklılıklar büyük ölçüde genetik yapıdan kaynaklandığını bildirmiştir Fick (1978).

Yağ verimi ise, 44,8-111,9 $\mathrm{kg} \mathrm{da}^{-1}$ arasında değişmiştir. En yüksek dekara yağ verimi Bosfora çeşidinden (111,9 $\left.\mathrm{kg} \mathrm{da}^{-1}\right)$, en düşük dekara yağ verimi ise ERZ 10-3 hattından (44,8 $\left.\mathrm{kg} \mathrm{da}^{-1}\right)$ elde edilmiştir. Farklı araştırmalarda yağ oranları \%31-54, yağ verimleri ise 82-199 $\mathrm{kg} \mathrm{da}^{-1}$ arasında bulunmuştur (Oral ve Kara., 1989; Kara, 1991; Tozlu ve ark., 2008; Sefaoğlu ve ark., 2009; Acar ve ark., 2011; Çil ve ark., 2011; Evci ve ark., 2011; Kyrychenko ve Kolomatska, 2011; Albayrak, 2014). Bütün yağ bitkilerinde ekonomik açıdan en önemli verim kriteri yağ verimidir. Tane verimi ve yağ oranının bir bileşkesi olan yağ verimi, çeşit özelliği olarak ortaya çıktı̆̆ gibi, tane verimi ve yağ oranını etkileyen kültürel uygulamalar ve ekolojik faktörlere bağlı olarak yağ oranı ve yağ veriminin azaldığ 1 farklı araştırmacılar tarafından vurgulanmaktadır (Haris ve ark., 1978; Albayrak, 2014). Çalışmada elde edilen sonuçlar ile araştırmacıların elde ettiği sonuçlar arasında benzerlikler ve farklılıklar görülebilmektedir. Oluşan farklılıkların Albayrak (2014), Haris ve ark (1978)' in belirttiği sebeplerden oluşabileceği düşünülmektedir.

\section{SONUÇ VE ÖNERILER}

Bu çalışma, Doğu Anadolu Tarımsal Araştırma Enstitüsü Müdürlüğü tarafından bölgenin ekolojik koşullarına uygun yağlık ayçiçeği çeşit geliştirme çalışmaları kapsamında yürütülmüştür. Araştırmada yedi adet hat ile standart olarak kullanılan LG 558, BOSFORA VE 08 TR 003 çeşidi verim ve verim unsurları bakımından karşılaştırılmıştır. Yapılan çalışma sonucunda incelenen bitkisel ve teknolojik özellikler bakımından yağlık ayçiçeği genotipleri arasında önemli farklılıklar belirlenmiştir. Araştırmada kullanılan ayçiçeği çeşit ve hatlarında BOSFORA, ERZ 10-24 VE ERZ 10-11 genotiplerinin diğer hat/çeşitlere göre daha üstün olduklarını söylemek mümkündür. Üstün olan bu hatlarla çalışmalara devam edilmesine ve bu hatların bölge verim denemelerine aktarılmasına karar verilmiştir.

\section{KAYNAKLAR}

Acar, M., Gizlenci, Ş., Öner, E,K., 2011. Sunflower breeding studies in blakcsea area. Sunflower breeding and adaptation studies in cukurova region. International Symposium On Sunflower Genetic Resources, October 16 - 20, 2011, S,47, Kuşadası, İzmir, Turkey.

Albayrak, Ş,N., 2014. Ekim zamanlarına göre uygulanan değişik azotlu gübre formlarının yağlık ayçiçeği (Helianthus Annuus L,) çeşitlerinin verim ve verim unsurlarına etkisi. Atatürk Üniversitesi Fen Bilimleri Enstitüsü, Yüksek Lisans Tezi.

Andrei, E., Ivancia, V., Barnaveta, E., Tarnauceanu, D., 1992. Aspects and directions on seed production of sunflower in lasi County. Cercetari Agronomice in Moldova, 25 (1): 248-252.

Carter, F,C., 1978. Sunflower Science and Technoloby, American Society of Agronomy. Madison, Wisconsin, USA, p 505.

Çil, A,N., Çil, A., Evci, G., Kaya, Y., 2011. Sunflower breeding and adaptation studies in cukurova region. International Symposium On Sunflower Genetic Resources, October 16 - 20, 2011, S,53, Kuşadası, İzmir, Turkey.

Demirel, A., 2014. Kırşehir ekolojik koşullarında bazı yağlık ayçiçeği çeşitlerinin verim ve verim öğelerinin belirlenmesi. Ahi Evran Üniversitesi Fen Bilimleri Enstitüsü, Yüksek Lisans Tezi.

Esechie, H,A., Elias, S., Rodribez, V., and Alasmi, H,S., 1996. Response of sunflower (Helianthus annuus L,) to planting pattern and population density in a desert climate. J, Of Agric, Sci., Camb., 126: 455-461.

Evci, G., Pekcan, V., Yılmaz, İ,M., Kaya, Y., Şahin, İ., Çıtak, N., Tuna, N., Ay, O., Pilaslı, A., 2011. Ayçiçeğinde (Helianthus annuus L,) yă̆ kalitesi ve verim öğeleri arasındaki ilişkilerin belirlenmesi. Türkiye IX, Tarla Bitkileri Kongresi, S,279, Bursa. 
Fick, G,N., 1978 . Selection for self-fertility and oil percentage in development of sunflower hybrids. Proc, VIII,Int, Sunflower Conf, 418-422.

Gül, V., Kara K., 2015. Effects of dífferent nitrogen doses on yield and quality traits of common sunflower (Helianthus annuus $L$,). Turkish Journal of Field crop 2015, 20(2), 159-165.

Haris, H,C., J,R, Mc William and W,K, Mason, 1978. Influence of temperature on oil content and composition of sunflower seed. Aust, J, Agric, Res, 29: 1203-1212.

Kara, K.,1986. Erzurum ekolojik koşullarında bazı yağlık ayçiçeği (Helianthus annus L,) çeşitlerinin fenolojik, morfolojik özellikleriyle verim ve verim öğeleri üzerinde bir araştırma. Doğa Türk Tarım ve Ormancılık Dergisi, 1: 366-377.

Kara, K, 1991. Bazı Yerli ve Yabancı Yağlık Ayçiçeği (Helianthus annus L,) çeşitlerinin zirai karakterleri üzerine bir araştırma. Atatürk Üniversitesi Ziraat Fakültesi Dergisi 22(2), 62-77, Erzurum.

Kara, K., Öztürk, E., Polat, T., 2013. Farklı yetişme sürelerine sahip yağlık ayçiçeği çeşitlerinin kuru ve sulu koşullarda kışlık (dondurma) ve yazlık olarak yetiştirilmesi üzerine bir araştırma. Türkiye 10. Tarla Bitkileri Kongresi, 10-13 Eylül 78-85, Konya.

Karaaslan, D., 2003. Diyarbakır koşullarında yetiştirilebilecek ayçiçeği çeşitlerinin belirlenmesi. Türkiye 5. Tarla Bitkileri Kongresi, 13 - 17 Ekim, Diyarbakır, 245-249.

Karakuş, A., Kaya, C., Sefaoğlu, F., 2014. Bazı yağlık ayçiçeği (Helianthus annus L,) çeşit adayı ve çeşitlerinin Erzurum koşullarında adaptasyon kabiliyetlerinin belirlenmesi. Enerji Tarımı ve Biyoyakıtlar 4, Ulusal Çalıştayı, 28-29 Mayıs 2014 Samsun, 115-122.

Kyrychenko, V,V., Kolomatska, V,P., 2011. Results of the scientific program for sunflower breeding, sunflower breeding and adaptation studies in Çukurova region, international symposium on sunflower genetic resources. October $16-20$, 2011, S,26, Kuşadası, İzmir, Turkey.

Oral, E., Kara, K., 1989. Erzurum ekolojik koşullarında bazı yağlık ayçiçeği (Helianthus annuus L,) çeşitleri üzerinde bir araştırma. Doğa, Türk Tarım ve Ormancılık Dergisi. 13 (2), S, 342-355.

Özer, H., 1999. Bazı Yağlık Ayçiçeği (Helianthus annus L,) Çeşitlerinin Erzurum ekolojik koşullarında adaptasyonu ve önemli tarımsal özelliklerinin incelenmesi. (Yüksek lisans tezi, Basılmamış), Atatürk Üniversitesi, Fen Bilimleri Enstitüsü, Erzurum.

Özer, H., Öztürk, E., Polat, T., 2003. Determination of the agronomic performances of some oilseed sunflower (Helianthus annuusL, ) hybrids grown under Erzurum ecological conditions. Turk J Agric For, 27 (2003) 199-205.

Sefaoğlu, F., Özer, H., Öztürk, E., Polat, T., 2009. Erzurum ekolojik koşullarında bazı yağlık ayçiçeği çeşitlerinin adaptasyonu ve önemli tarımsal özelliklerinin belirlenmesi. Türkiye VIII, Tarla Bitkileri Kongresi, 19-22 Ekim.

Tan, A,Ş., 2010, Ayçiçeği tarımı, T,C, gıda, tarım ve hayvancılık bakanlığı tarımsal araştırmalar genel müdürlüğü ege tarımsal araştırma enstitüsü müdürlüğü. Çiftçi Broşürü No: 136.

Tan, A,Ş., 2014. Bazı yağlık ayçiçeği çeşitlerinin Menemen ekolojik koşullarında performansları. Journal of Aegean Agricultural Research Institute 24 (1), 1-24.

Tozlu E., Dizikısa T., Kumlay A,M., Okçu M., Pehluvan M, ve Kaya C., 2008. Erzurum-Pasinler ekolojik koşullarında yetiştirilen bazı yağlık ayçiçeği (Helianthus annuus L,) hibridlerinin agronomik performanslarının belirlenmesi. Ankara Üniversitesi, Ziraat Fakültesi, Tarım Bilimleri Dergisi, 14(4) 359-364.

Tuncturk, M., T, Eryigit and İ, Yilmaz, 2005. A research on determination of yield and some yield components of some sunflower varieties (Helianthus annuusL,) in Van-Erciş conditions. VI, Turkish Field Crops Congress, 5-9 September, 2005, pp, 41-44, Antalya, Turkey (in Turkish).

Tuik, 2016, www,tuik,gov,tr, erişim tarihi 22.03.2016

Yıldız, G., Özer, H., Polat, T., Öztürk, E., Sefaoğlu, F., 2009. Farklı ekim zamanlarının yağlık ayçiçeğinin verim ve tarımsal özellikleri üzerine etkisi. Türkiye VIII, Tarla Bitkileri Kongresi, 19-22 Ekim 2009, Hatay/Türkiye. 